\title{
JUURNAL.RU
}

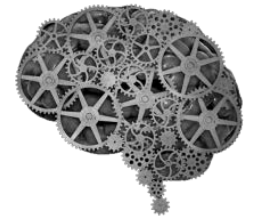

COMPANY GROUP "INTELLEKT"

Васильев С.А. Национальньй исследовательский университет «Московский институт электронной техники» Зеленоград, Россия

doi: 10.18411/lj2016-7-2-01

idsp 000001: lj2016-16-2-01

\section{Исследование эффективности некоторых схемотехнических решений, построенных на проходной КМОП-логике}

Количество выходов демультиплексора будем обозначать верхним задним индексом, т.е. двухвыходовой мультиплексор обозначается DMX2. Будем обозначать заранее определенное значение выходов нижним задним индексом, т.е. DMX с заранее определенным значением 0 - это DMX0, DMX с заранее определенным значением 1 - это DMX1.

Если вход D является инверсным, то это будет обозначаться знаком минус в верхнем переднем индексе, например, -DMX2 имеет инверсный вход и два выхода.

Формула DMX02 (двухвыходового с заранее определенным значением 0):

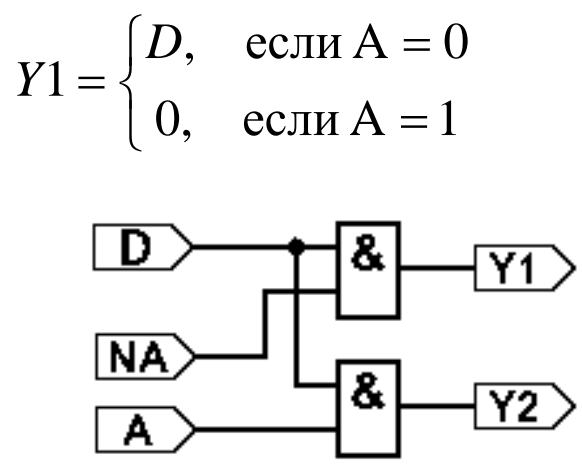

Рис.1. DMX02. Реализация на логических элементах.
$Y 2= \begin{cases}D, & \text { если } \mathrm{A}=1 \\ 0, & \text { если } \mathrm{A}=0\end{cases}$

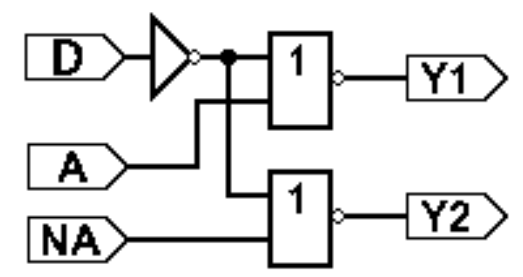

Рис.2. DMX02. Реализация на логических КМОП элементах. 
Формула DMX12 (с заранее определенным значением 1):

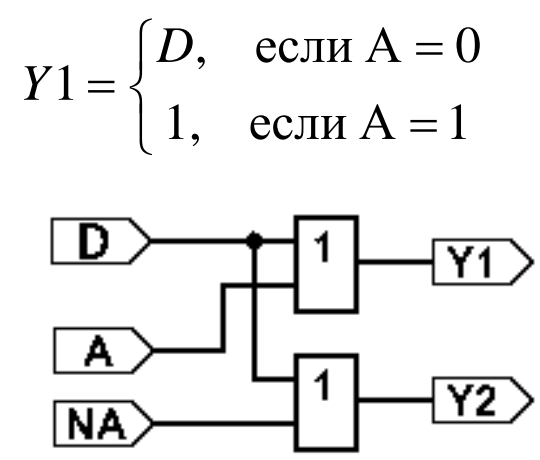

Рис.3. DMX12. Реализация на логических элементах.

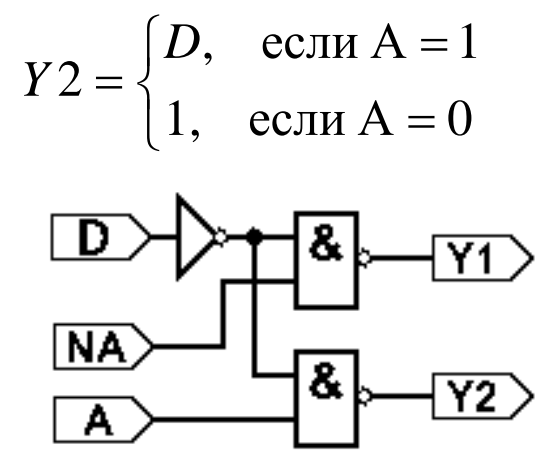

Рис.4. DMX12. Реализация на логических КМОП элементах.

По определению, двоичный дешифратор с $\mathrm{K}$ входами и $\mathrm{N}$ выходами работает следующим образом. На входы дешифратора подается слово из К бит. Количество допустимых входных комбинаций 2 К. На выходах дешифратора формируется двоичное слово из $\mathrm{N} \leq 2 \mathrm{~K}$ бит. В выходном слове всегда имеется один активный бит с заранее определенным состоянием, а все остальные биты называются неактивными и имеют свое заранее определенное состояние, не совпадающее с активным битом. В нашем случае активный бит будет равен 1 , а неактивные биты будут равны 0.

Классический способ построения дешифратора - это построение из вентилей И, в КМОП технологии это вентили ИЛИ-НЕ. Для дешифратора имеющего $\mathrm{N}$ выходов и К адресных входов, требуется $\mathrm{N}$ одинаковых вентилей, каждый из которых будет иметь $\mathrm{K}$ входов, при этом каждый из $\mathrm{K}$ входов подсоединяется к соответствующему адресному входу (прямому или инверсному). 


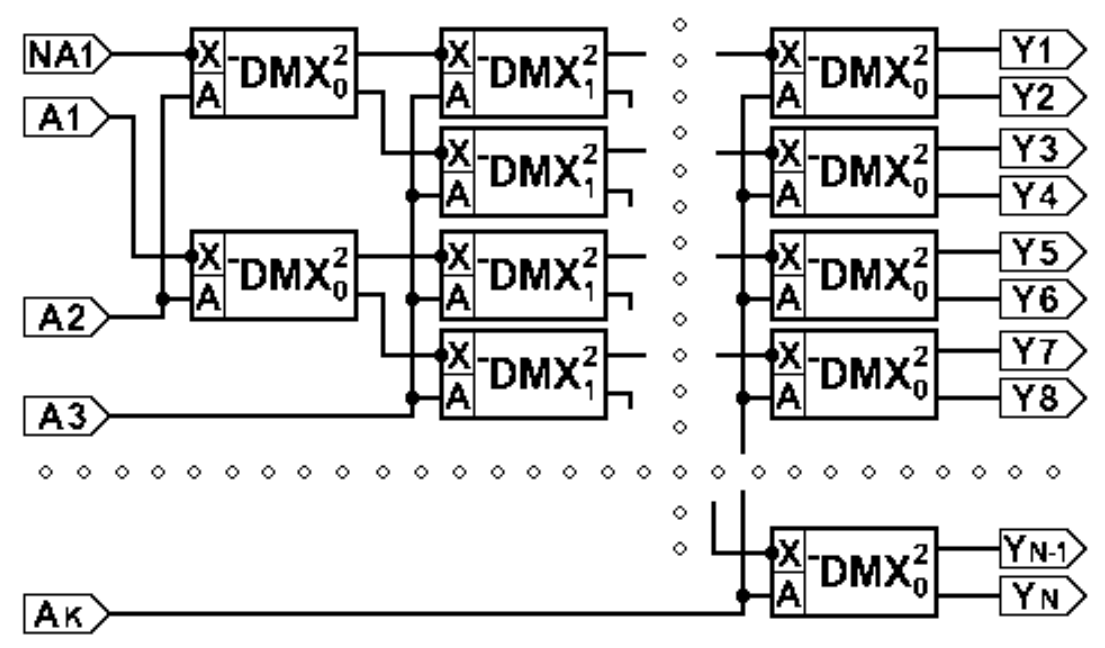

Рис.5. Принцип построения N-выходового дешифратора в виде бинарного дерева, если К - четное.

Результаты моделирования демультиплексоров приведены в Таблице 1.

Таблииа 1

Результаты моделирования демультиплексоров.

\begin{tabular}{|c|c|c|c|}
\hline Название схемы. & $\begin{array}{c}\text { Средняя задержка } \\
\text { переключения (пс) }\end{array}$ & $\begin{array}{c}\text { Максимальная частота } \\
\text { (МГц) }\end{array}$ & $\begin{array}{c}\text { Ток потребления на } \\
\text { частоте 500 МГц (мА) }\end{array}$ \\
\hline -DMX02 & 29.95 & 1000 & 523 \\
\hline -DMX12 & 103.7 & 1000 & 738 \\
\hline DMX02 & 39.05 & 770 & 980 \\
\hline DMX02 (транзисторы) & 30 & 1330 & 330 \\
\hline DMX12 & 92.3 & 500 & 960 \\
\hline DMX12 (транзисторы) & 41.45 & 1000 & 570 \\
\hline
\end{tabular}

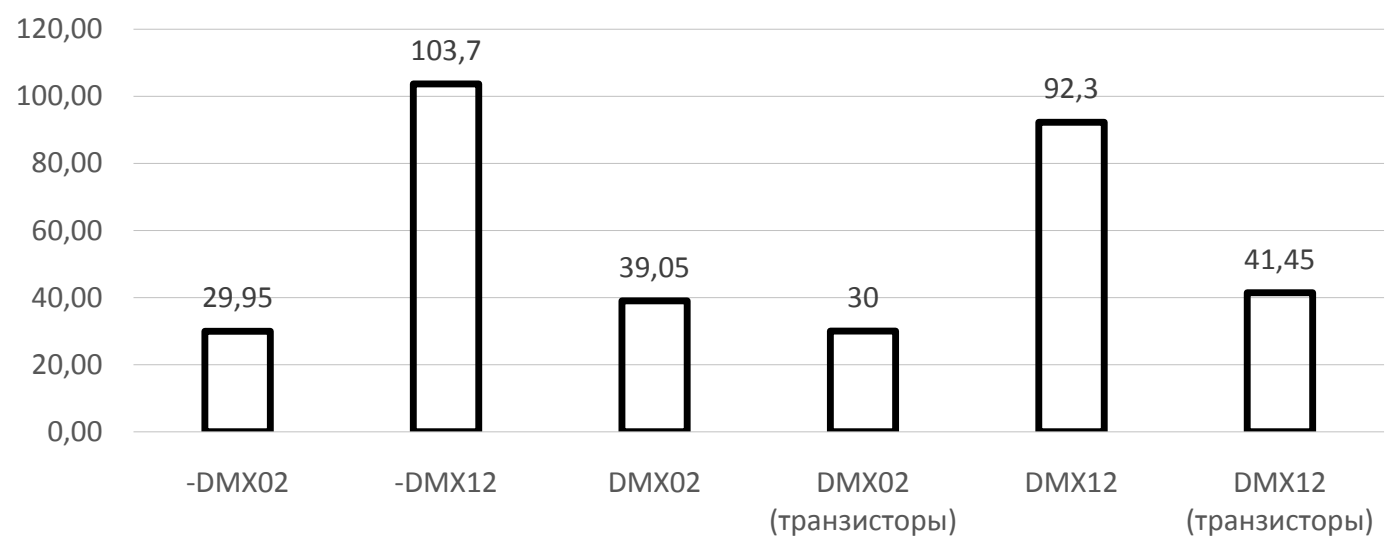

Рис.6. Диаграмма средней задержки переключения (пс). 


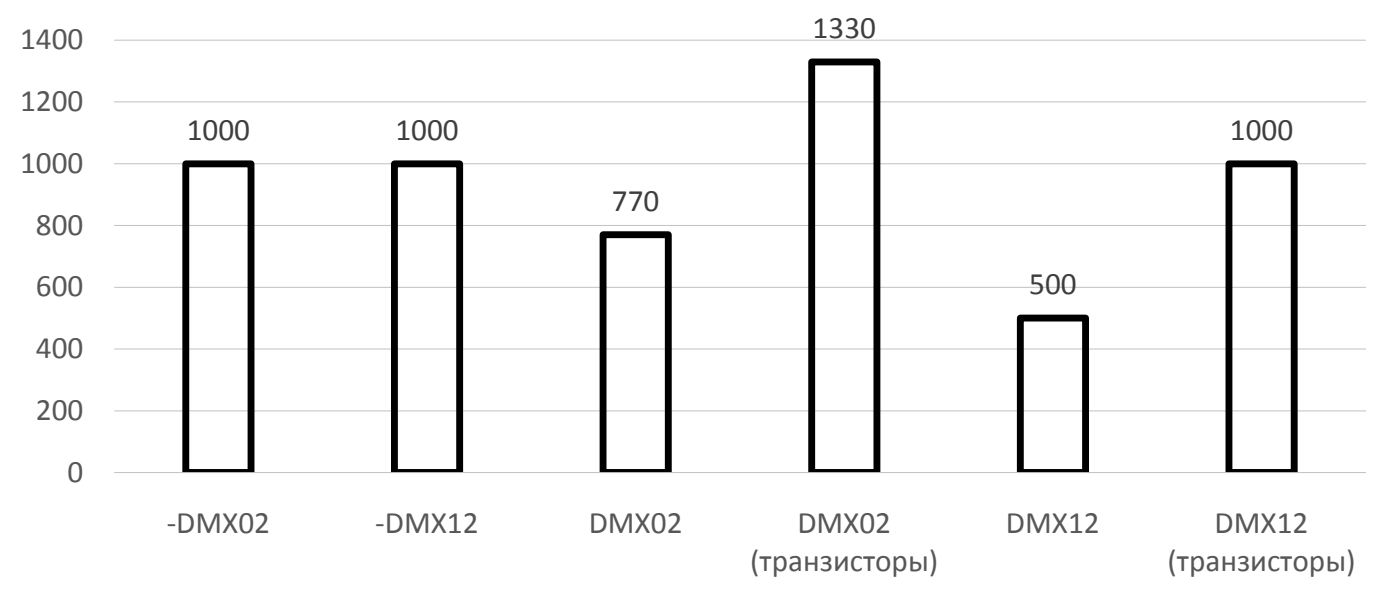

Рис.7. Диаграмма максимальной частоты работы(МГц).

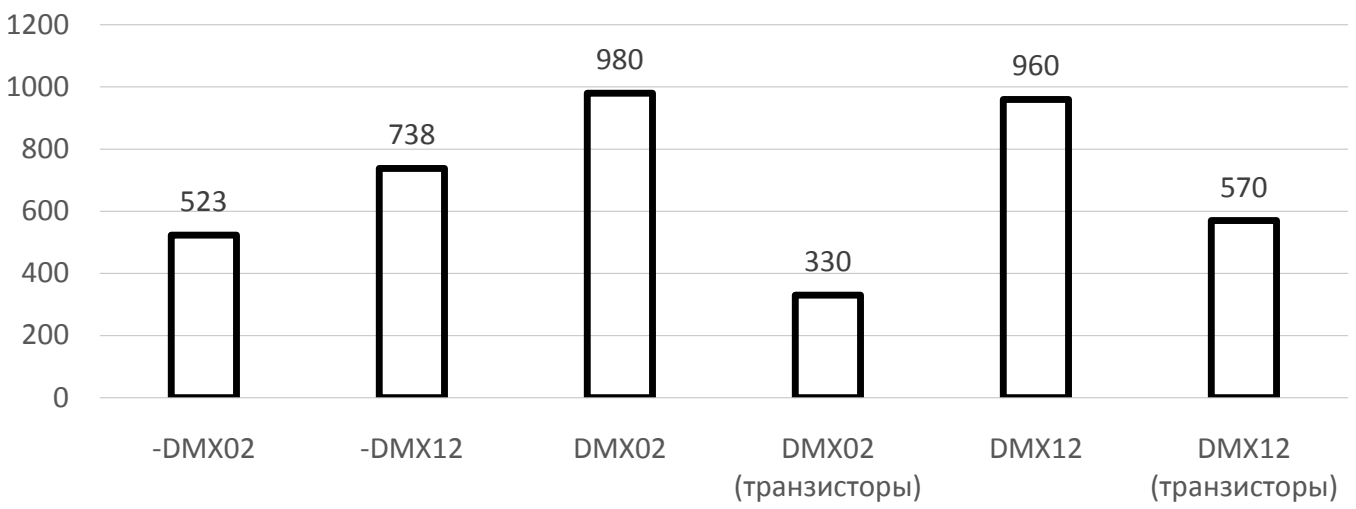

Рис.8. Диаграмма тока потребления на частоте 500МГц (мА).

Результаты моделирования дешифраторов приведены в таблице 2.

Таблица 2

Результать моделирования дешифраторов.

\begin{tabular}{|c|c|c|c|}
\hline Название схемы. & $\begin{array}{c}\text { Средняя задержка } \\
\text { переключения (нс) }\end{array}$ & $\begin{array}{c}\text { Максимальная частота } \\
(\text { МГц) }\end{array}$ & $\begin{array}{c}\text { Ток потребления на } \\
\text { частоте 570 МГц (мА) }\end{array}$ \\
\hline Принципиальная схема. & 0,135 & 800 & 4,7 \\
\hline КМОП & 0,16 & 670 & 2,4 \\
\hline Бинарное дерево. & 0,075 & 570 & 4,6 \\
\hline Проходные ключи. & 0,075 & 670 & 2,7 \\
\hline
\end{tabular}




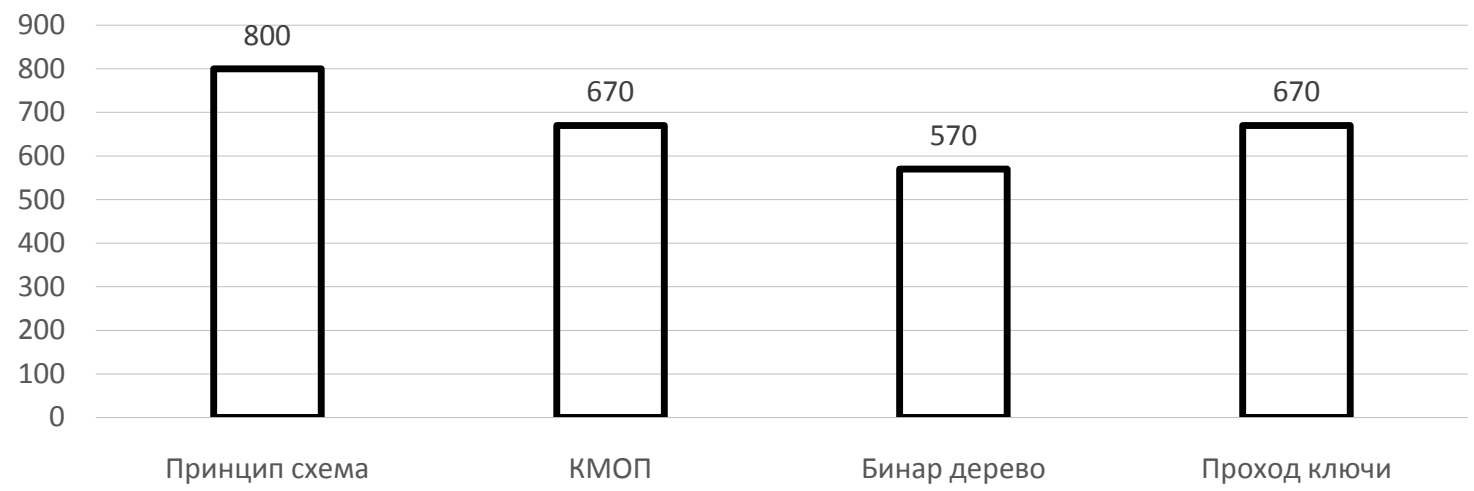

Рис.9. Диаграмма максимальной частоты работы (МГЦ).

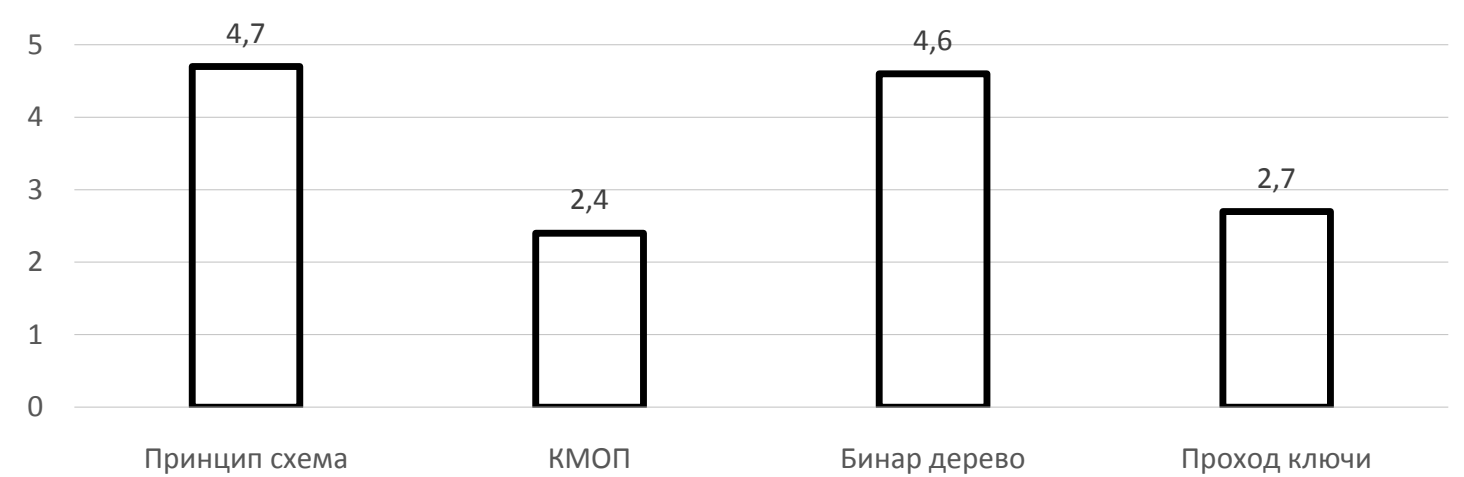

Рис.10. Диаграмма тока потребления (мА).

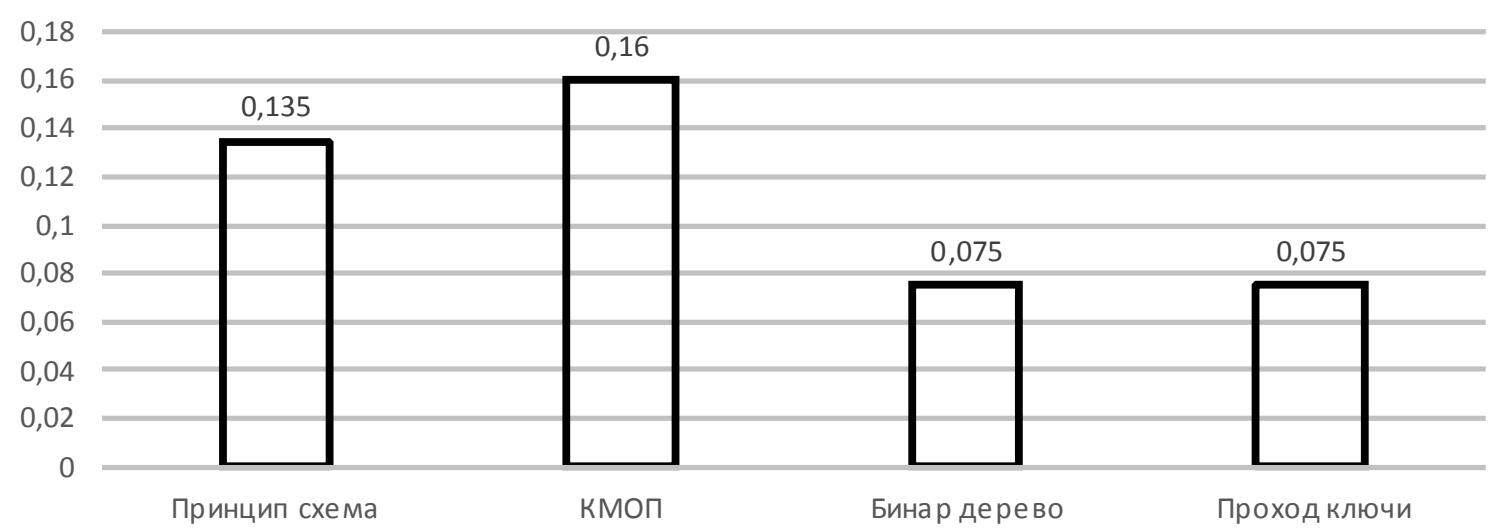

Рис.11. Диаграмма средней задержки переключения (нс). 


\section{Литература:}

1. Цифровые интегральные схемы. Методология проектирования (Боривож Николич, Жан Рабаи, Ананта Чандракасан.) 2007г.

2. Прянишников В.А. Электроника: Полный курс лекций: Учебник для вузов. СПб., 2003.

3. А.А.Миндеева Учебное пособие Микросхемотехника МИЭТ 2004. 